\title{
ROMANIAN CARBONATE ROCKS CUTTABILITY ASSESSMENT USING LINEAR CUTTING TESTER
}

\author{
Andrei ANDRAS ${ }^{1 *}$, Florin Dumitru POPESCU ${ }^{2}$ \\ ${ }^{1}$ University of Petroșani, Petroșani, Romania, andrei.andras@gmail.com \\ ${ }^{2}$ University of Petroșani, Petroșani, Romania, fpopescu@gmail.com
}

DOI: $10.2478 / \operatorname{minrv}-2021-0034$

Keywords: microwave, excavation, carbonate rocks, point attack picks, mechanical properties, linear cutting test

Abstract: The paper presents the state-of-the-art on the microwave assisted mechanical rock cutting by presenting actual findings and tendencies in the field in international literature, and the activities performed during the intermediate stage and the results obtained by the team from the University of Petroșani as partner within the ERAMIN-ERANET-MIWACUT research project.

\section{Introduction}

In general, mechanical excavation, hard rock cutting and drilling and blasting are the most common methods / technologies when it comes to rock mass extraction. Mechanical cutting or excavation is more advantageous as compared to the classic drilling and blasting for a number of reasons: continuous exploitation versus cyclic one, less effect on the surrounding rock mass, better safety and less environmental impact. However, the technical limitation of the mechanical machines in certain geotechnical conditions is the biggest disadvantage. With the scope of overcoming these limitation, as well as production increase, excavation tools wear reduction or replacement of the drill and blast method, there are numerous approaches researched today.

One of these is the use of microwave treatment of the rocks prior to excavation / cutting. Rock absorbs the microwaves thus the electromagnetic energy is converted to heat, which leads to cracks and changes of the rock mass properties. Microwave treatment is proved to decrease the strength of rocks [1-3]. Research on various types of rocks was conducted [4], such as basalt [5], granite [6]. Experimental research as well as numerical approaches on the topic of microwave-induced fracturing of rocks was conducted by scholars worldwide [7-11]

Microwave-assisted mechanical rock cutting is still in laboratory and experimental phases, with the proposed schema as shown in Figures 1 and 2.

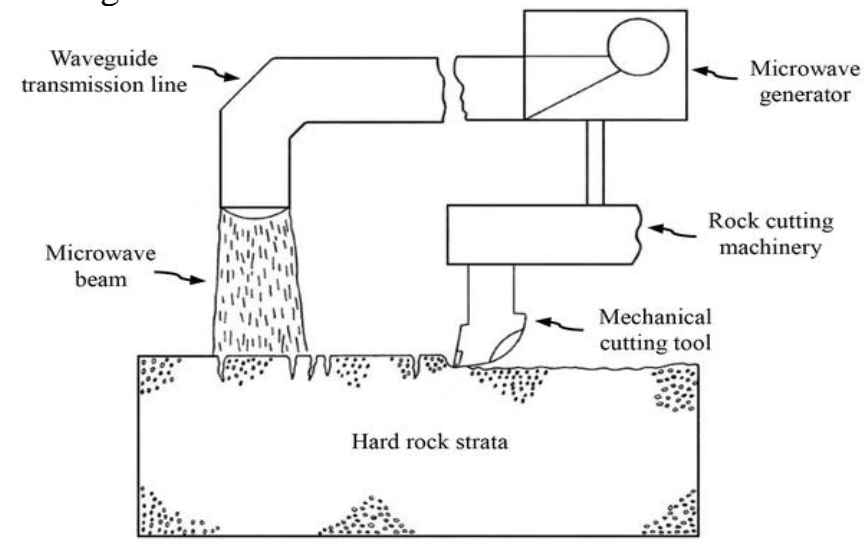

Fig.1. Schematic diagram of microwave-assisted mechanical rock cutting [12]

\footnotetext{
* Corresponding author: Andraș Andrei, assoc.prof. Ph.D. eng., University of Petrosani, Petrosani, Romania, (University of Petrosani, 20 University Street, andrei.andras@gmail.com)
} 


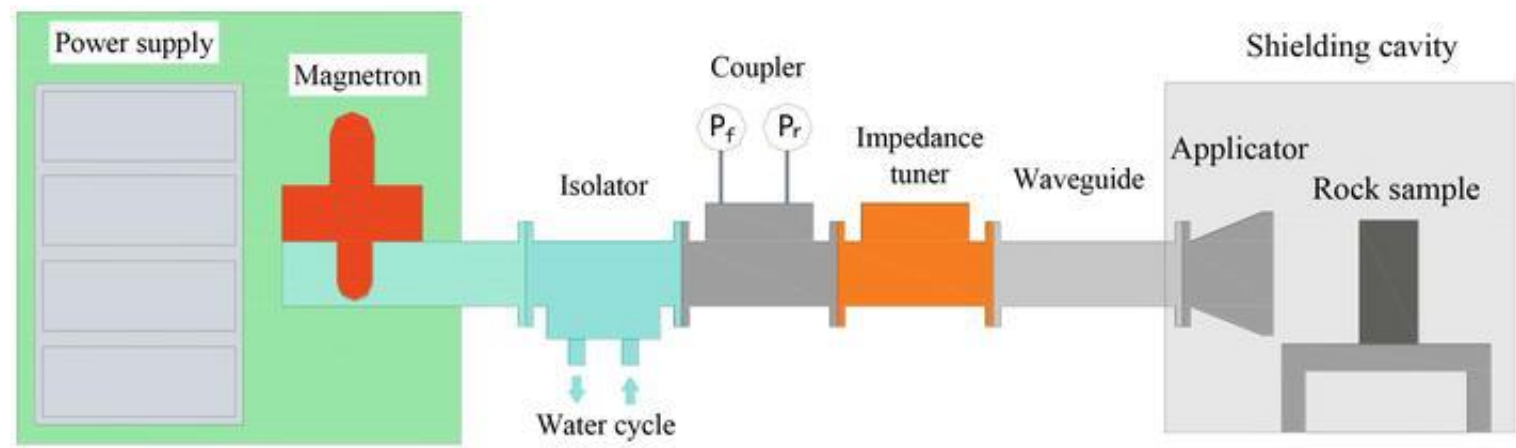

Fig.2. Schematic view of the microwave heating system [13]

\section{Experimental work carried out}

\subsection{Previous work conducted within the project}

In the precedent stages of the research, samples of carbonate rocks (Ruschița Marble, Bășchioi and Podeni limestone) were prepared for both UCS and BTS test as well as linear cutting tests both for abroad partners in the project as well as in-house testing at Petroșani. Their mineralogical, petrographic and physical mechanical characteristics were established using standard testing methods in the laboratories of University of Petroșani.

\subsection{Test carried out within current stage of the project}

In the present stage, linear cutting tests were performed in the laboratory of the University of Petroşani, using rectangular samples from all three locations of sampling. The tests were performed using point attack bits (Figure 3), without microwave assistance, using an in-house force measurement solution developed using 1-D load cells (Figure 4), based on technology presented in [14].

Results from this testing will be compared to test carried out by consortium partners in the project in the next stage, as well as with results of numeric simulation to be carried out.
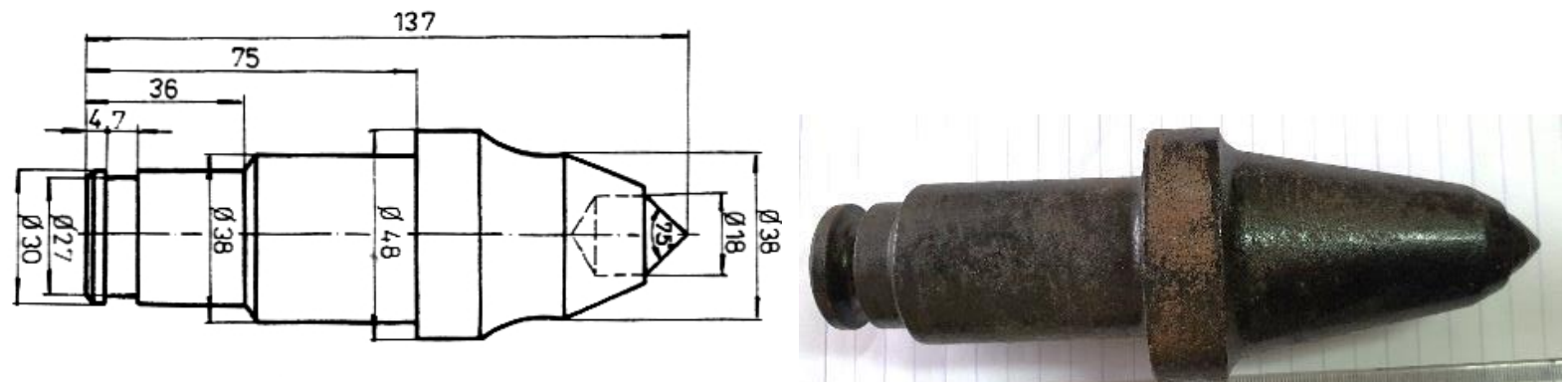

Fig.3. Point attack bits used

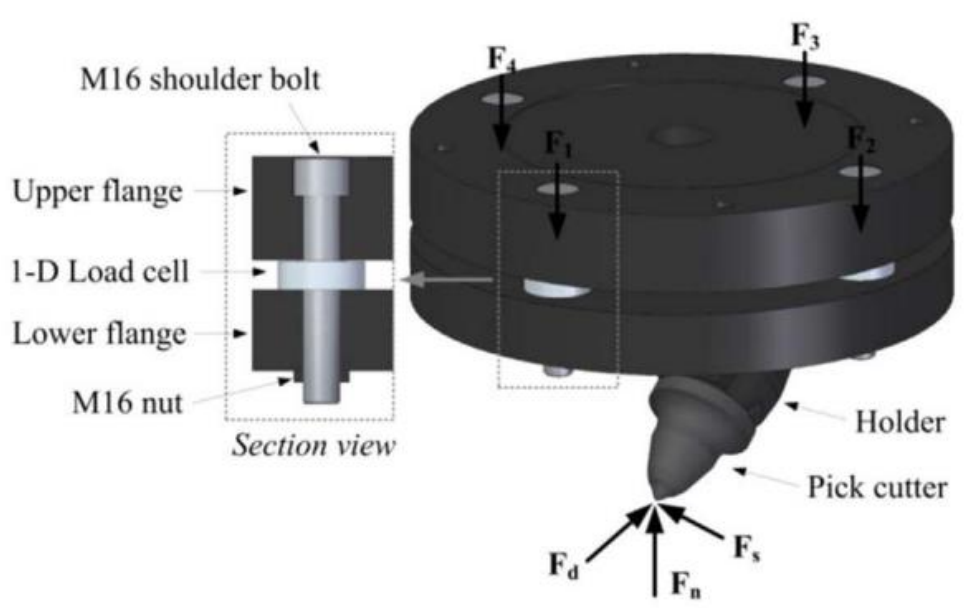

Fig.4. Measurement solution proposed [14] 
With this system, samples of marble and limestone were subjected to cuts at different depths of cut, and the tangential, normal and lateral components (Fx, Fy şi Fz) of the force were recorded. Fx is the tangential force and is acting in the direction of the pick movement, Fy, is the normal force, acting perpendicular to the cutting plane and Fz, is the lateral force, acting in a direction perpendicular to the first two.

To make an initial estimate of the cutting forces, the Evans [15] model of the tangential cutting force was used, according to the relation:

$$
F t=\frac{16 \cdot \pi \cdot \sigma_{r t}^{2} \cdot h_{0}^{2}}{\cos (\alpha)^{2} \cdot \sigma_{r c}}
$$

where:

$\sigma_{\text {rc }}$ is the uniaxial compressive strength, $\mathrm{N} / \mathrm{m}^{2}$

$\sigma_{\mathrm{rt}}$ is the splitting tensile strength, by the Brazilian method, $\mathrm{N} / \mathrm{m}^{2}$

$\mathrm{h}_{0}$ is the cutting depth, $\mathrm{m}$

$\alpha$ is the point attack pick angle.

The results obtained for values of cutting depth between $1 \mathrm{~mm}$ and $15 \mathrm{~mm}$ for the three types of rocks are presented in the Table 1.

Table 1. Cutting test results

\begin{tabular}{|c|c|c|c|}
\hline \multirow{2}{*}{$\mathbf{h}_{\mathbf{0}}(\mathbf{m m})$} & \multicolumn{3}{|c|}{$\mathbf{F}_{\mathbf{t}}(\mathbf{k N})$} \\
\hline & Rușchița Marble & Bășchioi Limestone & Podeni Limestone \\
\hline 1 & 0.086 & 0.091 & 0.024 \\
\hline 2 & 0.342 & 0.363 & 0.094 \\
\hline 3 & 0.77 & 0.816 & 0.213 \\
\hline 4 & 1.369 & 1.451 & 0.378 \\
\hline 5 & 2.14 & 2.267 & 0.59 \\
\hline 6 & 3.081 & 3.264 & 0.85 \\
\hline 7 & 4.193 & 4.443 & 1.157 \\
\hline 8 & 5.477 & 5.803 & 1.511 \\
\hline 9 & 6.932 & 7.344 & 1.913 \\
\hline 10 & 8.558 & 9.067 & 2.361 \\
\hline 11 & 10.355 & 10.971 & 2.857 \\
\hline 12 & 12.324 & 13.057 & 3.4 \\
\hline 13 & 14.463 & 15.323 & 3.99 \\
\hline 14 & 16.774 & 17.772 & 4.628 \\
\hline 15 & 19.256 & 20.401 & 5.313 \\
\hline
\end{tabular}

The highlighted values in the Table, correspond to the depth of $10 \mathrm{~mm}(1 \mathrm{~cm})$ and represent the average value of the specific cutting resistance, $\mathrm{A}$, expressed in $\mathrm{kN} / \mathrm{cm}$.

Table 2. Specific cutting resistance obtained by regression formulae in [16]

\begin{tabular}{|c|c|c|c|}
\hline \multirow{2}{*}{ Rock type } & $\sigma_{\text {rc }}$ & $\sigma_{\text {rt }}$ & A \\
\cline { 2 - 4 } & $\mathbf{M P a})$ & $(\mathbf{M P a})$ & $\mathbf{( k N / \mathbf { c m } )}$ \\
\hline Marble Rușchița & 86 & 9.57 & 9.2 \\
\hline Limestone Bășchioi & 77 & 9.35 & 8.53 \\
\hline Limestone Podeni & 16.3 & 2,2 & 3.5 \\
\hline
\end{tabular}

In order to stay under the value of force offered by the LCM (Ft $<10 \mathrm{kN})$, for the samples of Rușchița marble and Bașchioi limestone it was decided to limit the tests to the value $\mathrm{h}_{0}$ of $1 \mathrm{~cm}$, and for samples of Podeni limestone, to $1.5 \mathrm{~cm}$.

There are empirical coefficients presented in literature for the correlation of the specific resistance A with $\sigma_{\mathrm{rc}}$ and $\sigma_{\mathrm{rt}}$ that are determined based on experimental tests.

Thus, in [16] for similar rocks and values of $\sigma_{\mathrm{rc}}$ and $\sigma_{\mathrm{rt}}$, the values of $9.2,8.53$, respectively $3.5 \mathrm{kN} / \mathrm{cm}$ result for A, as presented in Table 2. The differences are due to the imperfection of the Evans model. 


\section{Results and discussion}

The results of recorded measurements for all samples tested are presented in Figures 5 to 7 .

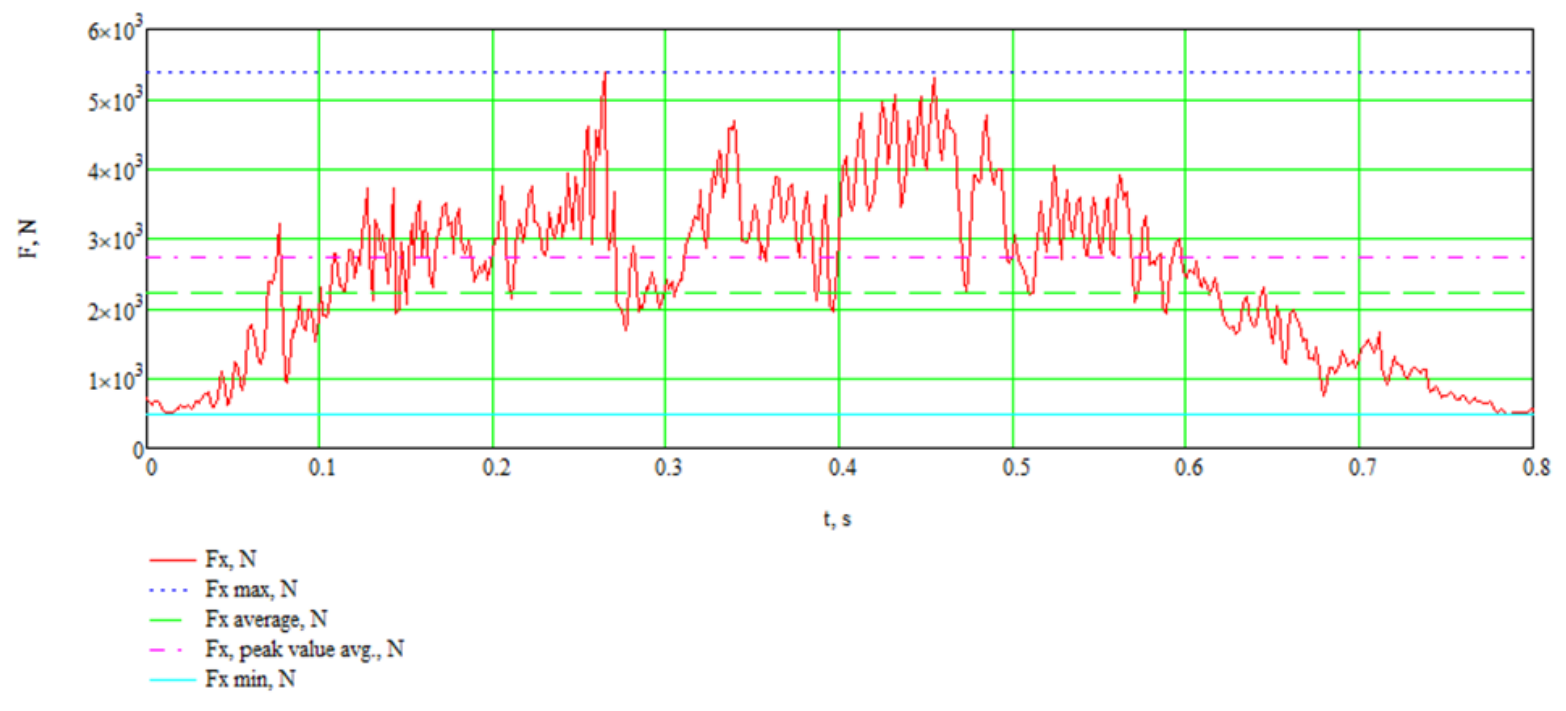

Fig. 5. Recorded measurements $F x$, Ruschita marble, $h 0=3 \mathrm{~mm}$
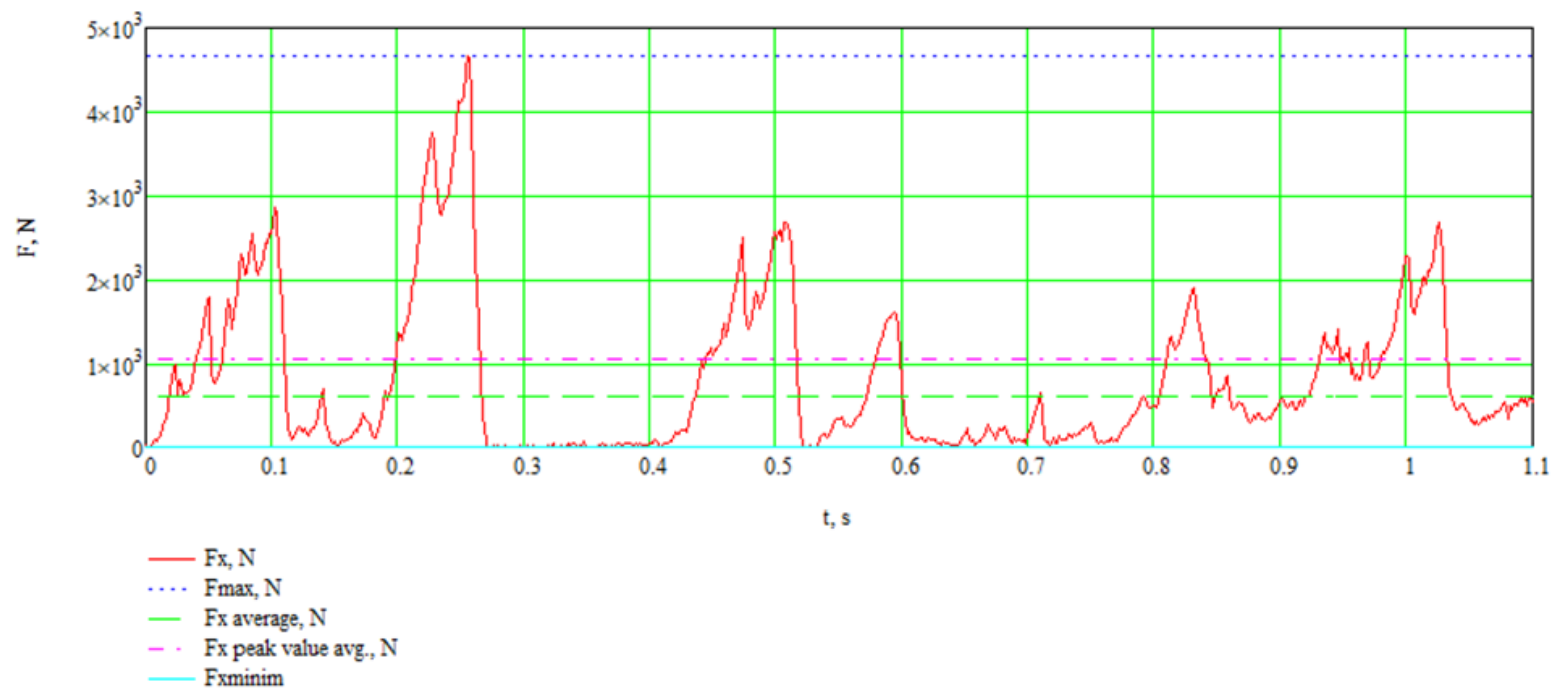

Fig. 6. Recorded measurements Fx, Bășchioi limestone, h0=3 mm

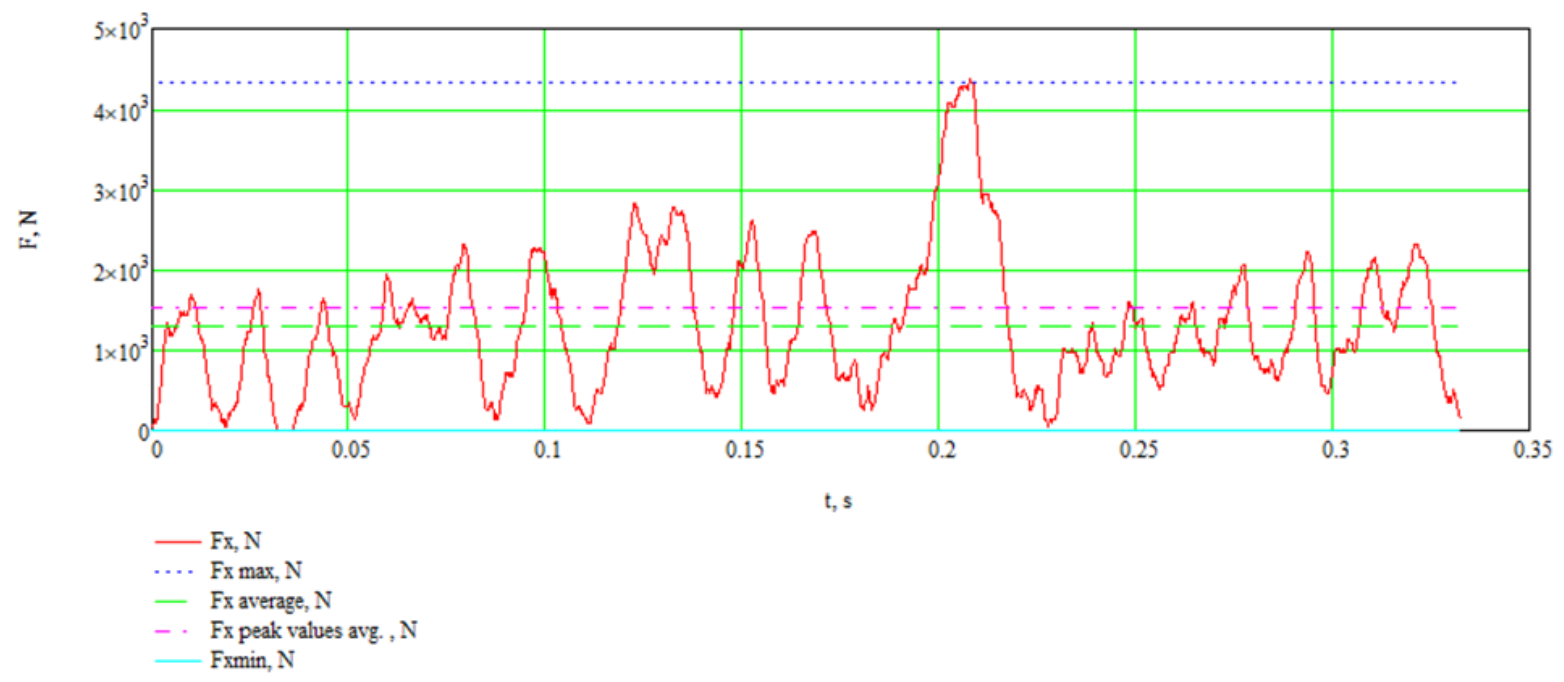

Fig. 7. Recorded measurements Fx, Podeni limestone, $h 0=5 \mathrm{~mm}$ 
vol. 27 , issue 4 / 2021

pp. 50-56 line.

The results were further processed statistically to highlight average measured values and the regression

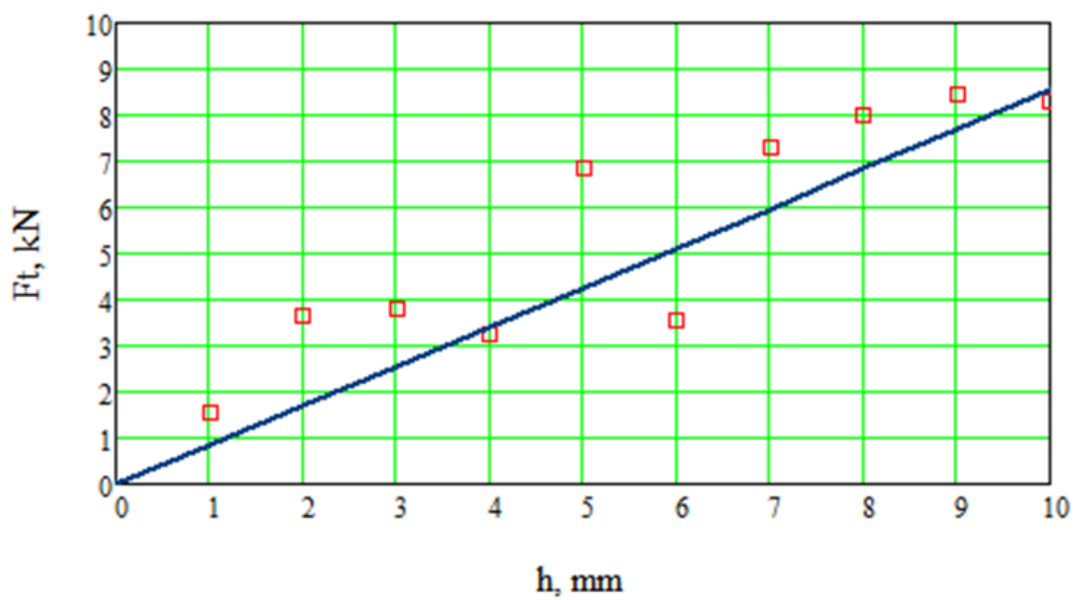

प्व Measured values

Regression line

Fig. 8. Average values obtained by measurement, and the regression line for Rușchița marble

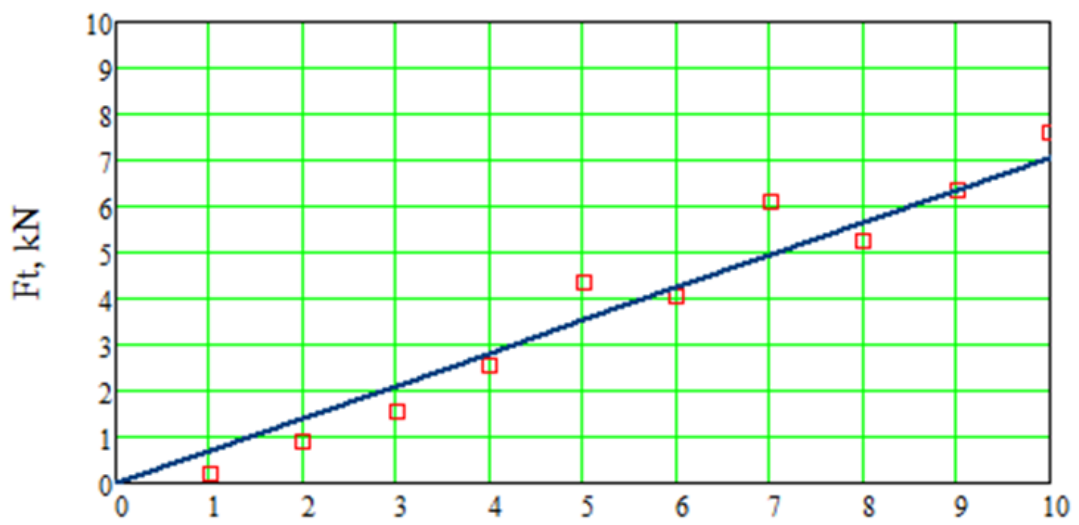

$\mathrm{h}, \mathrm{mm}$

प्व Measured values

- Regression line

Fig. 9. Average values obtained by measurement, and the regression line for Bășchioi limestone

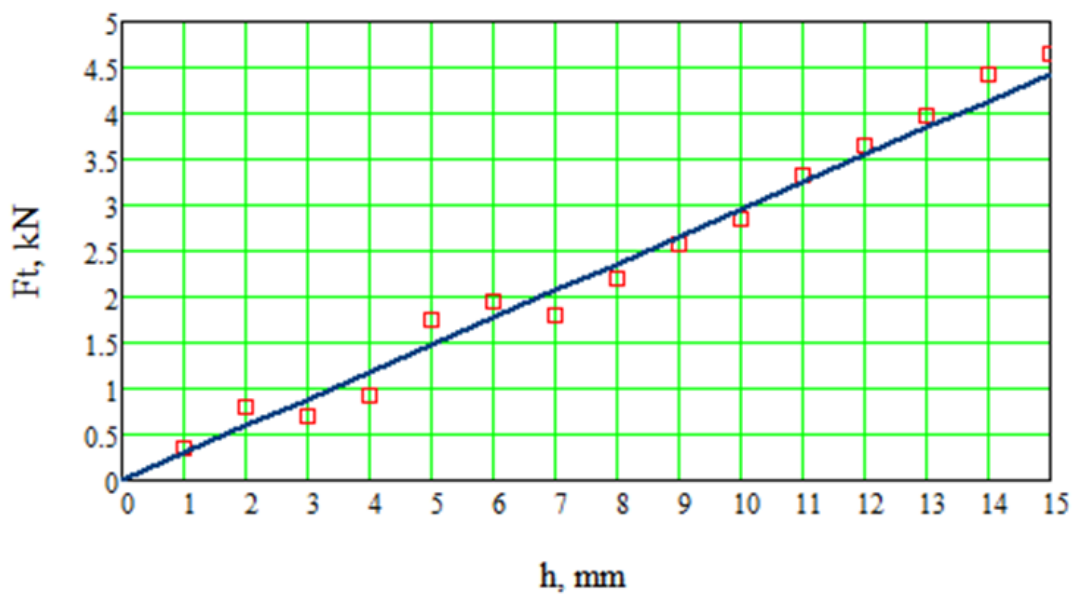

प्व Measured values

- Regression line

Fig. 10. Average values obtained by measurement, and the regression line for Podeni limestone 
Based on the data obtained, the average values of specific cutting resistance and specific cutting energy consumption of the three rock types, summarized in the Table 3 , were determined.

Table 3. Average values determined

\begin{tabular}{|c|c|c|c|}
\hline Rock type & \multicolumn{2}{|c|}{$\begin{array}{c}\text { Specific cutting } \\
\text { resistance }(\mathrm{kN} / \mathrm{cm})\end{array}$} & \multicolumn{2}{|c|}{$\begin{array}{c}\text { Specific cutting energy } \\
\mathrm{kWh} / \mathrm{m}^{3}\end{array}$} \\
\hline Marble Rușchița & 8,499 & 8,53 & 30,708 \\
\hline Limestone Bășchioi & 7,075 & 7,788 & 28,037 \\
\hline Limestone Podeni & 3,01 & 2,771 & 9,976 \\
\hline
\end{tabular}

\section{Conclusions}

On the basis of data for three types of rocks under study, using the inhouse built linear cutting system, the average values of cutting resistance and specific energy consumptions were determined.

The results are in line with literature, obtained for similar type of rocks, using similar or slightly different methods of measurement or / and estimation.

These are results of stage two of this research, and will serve as basis for comparison with values obtained by Consortium partners, in their tests, and further interpretation for the development of the microwave assisted linear cutting machine of carbonate rocks.

\section{Acknowledgements}

This work was supported by a grant of the Ministry of Research, Innovation and Digitization, CNCS/CCCDI - UEFISCDI, project number ERANET-ERAMIN-MIWACUT, within PNCDI III.

\section{References}

[1] Lu G.M., Li Y.H., Hassani F., Zhang X.W., 2016

Review of theoretical and experimental studies on mechanical rock fragmentation using microwave-assisted approach. Chinese Journal of Geotechnical Engineering, 38(8), pp. 1497-1506.

[2] Zheng Y.L., Ma Z.J., Zhao X.B., He L., 2020

Experimental investigation on the thermal, mechanical and cracking behaviours of three Igneous rocks under microwave treatment. Journal of Rock Mechanics and Rock Engineering.

[3] Hassani F., Nekoovaght P.M., Gharib N., 2016

The influence of microwave irradiation on rocks for microwave-assisted underground excavation. Journal of Rock Mechanics and Geotechnical Engineering, 8(1), pp. 1-15.

[4] Santamarina, J.C. (ed.), 1989

Rock excavation with microwaves: a literature review, Evanston, IL (etc.): Publ by ASCE.

[5] Hartlieb P., Leindl M., Kuchar F., Antretter T., Moser P., 2012

Damage of basalt induced by microwave irradiation. Special Issue - Physical Separation, Minerals Engineering, 31, pp. 82-89.

[6] Toifl M., Hartlieb P., Meisels R., Antretter T., Kuchar F., 2017

Numerical study of the influence of irradiation parameters on the microwave-induced stresses in granite. Minerals Engineering, 103-104(4), pp. 78-92.

[7] Hassani F., Nekoovaght P.M., Radziszewski P., Waters K.E., 2011

Microwave assisted mechanical rock breaking. Proceedings of the 12th ISRM International Congress on Rock Mechanics, Beijing: International Society for Rock Mechanics, pp. 2075-2080.

[8] Ali A.Y., Bradshaw S.M., 2011

Confined particle bed breakage of microwave treated and untreated ores. Minerals Engineering, 24(14), pp. 1625-1630. 
[9] Lu G.M., 2018

Experimental study on the microwave fracturing of hard rock. Thesis, Northeastern University.

[10] Kahraman S., Canpolat A.N., Fener M., 2020

The influence of microwave treatment on the compressive and tensile strength of igneous rocks. International Journal of Rock Mechanics and Mining Sciences, 129, 104303.

[11] Kahraman S., Canpolat A.N., Fener M., Kilic C.O., 2020

The assessment of the factors affecting the microwave heating of magmatic rocks. Geomechanics and Geophysics for Geo-Energy and Geo-Resources, 6(4), pp. 1-16.

[12] Lindroth D.P., Morrell R.J., Blair J.R., 1991

Microwave assisted hard rock cutting. US5003144 Patent.

[13] Lu G., Zhou J., 2021

Experimental Investigation on the Effect of Microwave Heating on Rock Cracking and Their Mechanical Properties, Microwave Heating - Electromagnetic Fields Causing Thermal and Non-Thermal Effects. Gennadiy I. Churyumov, IntechOpen, DOI: 10.5772/intechopen.95436. Available from: https://www.intechopen.com/chapters/75087

[14] Kang H., Cho J.W., Park J.Y., Jang J.S., Kim J.H., Kim K.W., Rostami, J., Lee, J.W. 2016.

A new linear cutting machine for assessing the rock-cutting performance of a pick cutter. International Journal of Rock Mechanics and Mining Sciences, 88, pp. 129-136. DOI:10.1016/j.ijrmms.2016.07.021.

[15] Evans A., 1984

Theory of the cutting force for point attack picks. International Journal of Mining Engineering, 2(1), pp. 63-71.

[16] Bilgin N., Demircin M.A., Copur H., Balci C., Tuncdemir H., Akcin N., 2006

Dominant rock properties affecting the performance of conical picks and the comparison of some experimental and theoretical results, International Journal of Rock Mechanics \& Mining Sciences, 43, pp. 139-156.

This article is an open access article distributed under the Creative Commons BY SA 4.0 license. Authors retain all copyrights and agree to the terms of the above-mentioned CC BY SA 4.0 license. 